Bài báo khoa học

\title{
Một số giải pháp nâng cao hiệu quả vận hành và giảm phát thải khí nhà kính, góp phần chống biến đổi khí hậu cho các nhà máy nhiệt điện và thủy điện đang vận hành của hệ thống điện Việt Nam trong bối cảnh mới
}

\author{
Lê Ngọc Sơn ${ }^{1}$ \\ ${ }^{1}$ Đại học Thủy lợi; lengson99@gmail.com \\ *Tác giả liên hệ: lengson99@gmail.com; Tel: +84-948172868
}

Ban Biên tập nhận bài: 12/6/2021 Ngày phản biện xong: 5/8/2021 Ngày đăng bài: $25 / 10 / 2021$

Tóm tắt: Hiện nay các nhà máy truyền thống là nhiệt điện than và thủy điện đang nắm vai trò chi phối trong cung cấp điện trong hệ thống điện ở nước ta. Tuy nhiên, trong vài năm gần đây và những năm tới, với sự cam kết về giảm phát thải nhà kính của quốc tế và Việt Nam có sự chuyển dịch nhanh chóng về cơ cấu năng lượng trong hệ thống điện và vai trò của các nhà máy điện truyền thống sẽ có thay đổi. Bài viết phân tích hiện trạng hệ thống điện và sự gia tăng của năng lượng tái tạo (mặt trời, gió) trong hệ thống, từ đó đưa ra đánh giá các giải pháp và đề xuất quan tâm ưu tiên hai trong nhóm giải pháp đối với các nhà máy đang vận hành là (i) nâng cấp hệ thống xử lý khí thải của một số nhà máy nhà máy nhiệt điện; (ii) nâng cao hiệu quả vận hành của hệ thống bậc thang thủy điện, góp phần giữ ổn định, giảm chi phí và phát thải khí nhà kính chung của của hệ thống điện.

Từ khóa: Hệ thống điện; Phát thải khí nhà kính; Hệ thống xử lý khí thải nhà máy nhiệt điện; Vận hành tối ưu hệ thống hồ chứa thủy điện.

\section{1. Đặt vấn đề}

Trong khoảng hai thập kỷ gần đây và sắp tới, do nhu cầu điện tăng rất nhanh, khoảng $10 \%$ hàng năm nên nhiều công trình nhiệt điện than và thủy điện đã và đang được xây dựng. Các nhà máy nhiệt điện đi vào vận hành từ năm 2000 tới nay có thể kể đến hàng chục nhà máy như Phả Lại 2, Hải Phòng 1\&2, Quảng Ninh 1\&2, Uông Bí $2 \&$ mở rộng $(\mathrm{MR})$, Mông Dương $1 \& 2$, Vĩnh Tân $2 \& 4$, Duyên Hải 1 , Nghi Sơn 1 , Thái Bình 1 và một số nhà máy đang xây dựng, trong đó có một số nhà máy đầu tư theo hình thức BOT sử dụng than nhập khẩu như Nghi Sơn 2, Vân Phong 1 sẽ đi vào vận hành trong thời gian tới. Các bậc thang hồ chứa thủy điện đã được hình thành trên toàn bộ các hệ thống sông chính ở nước ta (sông Đà, sông Cả, sông $\mathrm{Ba}$, sông Sê San, sông Đồng Nai, v.v.) đóng vai trò rất quan trọng trong cung cấp nước cho các ngành kinh tế, trong đó mang lại lợi ích phát điện và đảm bảo an ninh năng lượng rất lớn cho nền kinh tế của nước ta [1]. Sau Hội nghị Liên hiệp quốc về biến đổi khí hậu ở Paris (COP21) năm 2015, các nước trong đó có Việt Nam đã có cam kết về giảm phát thải khí nhà kính, chống biến đồi khí hậu $(\mathrm{BĐKH)}$. Việt Nam thể hiện cam kết cắt giảm phát thải của mình tới năm 2030 thông qua các mục tiêu tự cắt giảm $8 \%$ so với kịch bản phát thải thông thường quốc gia và lên tới $25 \%$ với sự hỗ trợ quốc tế [2]. Đặc biệt, những năm gần đây cam kết quốc tế về giảm phát thải càng mạnh mẽ hơn, cam kết cập nhật của Việt Nam xác 
định bằng nguồn lực trong nước, đến năm 2030 Việt Nam sẽ giảm $9 \%$ tổng lượng phát thải và có thể tăng đóng góp lên tới $27 \%$ khi nhận được hỗ trợ quốc tế thông qua hợp tác song phương, đa phương và thực hiện các cơ chế mới theo Thỏa thuận Paris về BĐKH [3-6].

Ở Việt Nam, Nghị quyết của Bộ Chính trị số 55-NQ/TW ngày 11/2/2020 về định hướng chiến lược phát triển năng lượng quốc gia của Việt Nam đến năm 2030, tầm nhìn đến năm 2045 (Nghị quyết 55) [7] đã đề ra nhiều mục tiêu giảm phát thải khí nhà kính từ hoạt động năng lượng so với kịch bản phát triển bình thường ở mức $15 \%$ vào năm 2030 , lên mức $20 \%$ vào năm 2045. Trong đó có các giải pháp rà soát tổng thể và có kế hoạch sớm triển khai nâng cấp công nghệ của các nhà máy điện than hiện có để đáp ứng yêu cầu bảo vệ môi trường, khuyến khích phát triển năng lượng tái tạo, nâng cao hiệu quả sử dụng và bền vững nguồn tài nguyên và năng lượng, nhằm đạt mục tiêu cam kết với quốc tế về giảm phát thải nhà kính.

Hiện nay thủy điện cùng với các nhà máy điện truyền thống sử dụng nhiên liệu than và khí đang nắm vai trò chi phối trong cung cấp điện. Tuy nhiên, trong vài năm gần đây và những năm tới, với sự cam kết về giảm phát thải nhà kính và giảm tỷ trọng nhiên liệu hóa thạch, nhất là nhiệt điện than của quốc tế và Việt Nam như đã nêu trên, có sự chuyển dịch nhanh chóng về cơ cấu năng lượng trong hệ thống điện và vai trò của các nhà máy điện than và thủy điện sẽ có thay đổi. Hiện nay Bộ Công thương cũng đang gấp rút hoàn thiện dự thảo đề án về Quy hoạch phát triển điện lực quốc gia thời kỳ 2021-2030, tầm nhìn tới năm 2045 (Quy hoạch điện VIII) [8] để trình Thủ tướng Chính phủ phê duyệt.

Nghiên cứu này sẽ đi vào phân tích hiện trạng, các giải pháp, tổng quan tình hình nghiên cứu cho từng giải pháp, từ đó làm rõ cơ hội nâng cấp hệ thống xử lý khí thải của một số nhà máy nhà máy nhiệt điện và nâng cao hiệu quả vận hành của hệ thống bậc thang thủy điện, góp phần giữ ổn định, giảm chi phí và phát thải khí nhà kính chung của của hệ thống điện.

\section{Phương pháp nghiên cứu}

\subsection{Hiện trạng hệ thống và đối tương nghiên cưu}

Theo Quy hoạch phát triển điện lực Quốc gia giai đoạn 2011-2020, tầm nhìn đến năm 2030 điều chỉnh (Quy hoạch điện VII) [1] dự kiến công suất đặt của hệ thống năm 2020 là $60 \mathrm{GW}$ (trong đó tỷ trọng thủy điện là 30,1\%; điện than là 42,7\%; năng lượng tái tạo là $9,9 \%$ ). Cũng theo Quy hoạch điện VII thì đến năm 200 thì tỷ trọng năng lượng tái tạo mới đạt đến $21 \%$ trong tổng công suất đặt $129,5 \mathrm{GW}$ trong khi thủy điện và nhiệt điện than lần lượt là $16,9 \%$ và $46,2 \%$. Với chính sách khuyến khích phát triển năng lượng phát thải thấp, nhất là năng lượng tái tạo, cơ cấu các nguồn phát điện đã có thay đổi rất lớn. Theo báo cáo của Viện Năng lượng, đến hết năm 2020 thì tổng công suất đặt của hệ thống là $69 \mathrm{GW}$ trong đó riêng mặt trời và gió đã chiếm khoảng $24 \%$, thủy điện $30 \%$, than $31 \%$ (Hình 1).

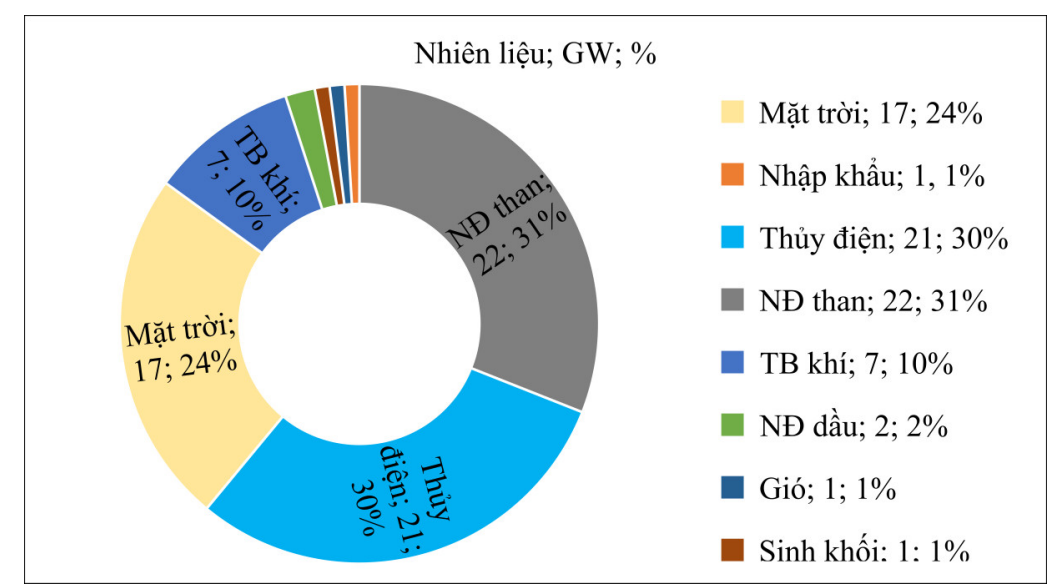

Hình 1. Cơ cấu công suất nguồn năm 2020 [8]. 
Phát thải khí nhà kính $(\mathrm{KNK})$ của quốc gia theo kịch bản phát triển thông thường quốc gia giai đoạn 2014-2030 là tổng hợp của 5 lĩnh vực: năng lượng, nông nghiệp, sử dụng đất, thay đổi sử dụng đất và lâm nghiệp (LULUCF), chất thải và các quá trình công nghiệp (IP) (Bảng 1).

Bảng 1. Kiểm kê khí nhà kính năm 2014 và kịch bản phát triển thông thường đến năm 2030 (Đơn vị: triệu tấn $\mathrm{CO}_{2}$ tđ) [9].

\begin{tabular}{ccccccc}
\hline Năm & Năng lượng & Nông nghiệp (AF) & LULUCF & Chất thải & IP & Tổng \\
\hline 2014 & 171,6 & 89,8 & $-37,5$ & 21,5 & 38,6 & 284,0 \\
2020 & 347,5 & 104,5 & $-35,4$ & 31,3 & 80,5 & 528,4 \\
2025 & 500,7 & 109,2 & $-37,9$ & 38,1 & 116,1 & 726,2 \\
2030 & 678,4 & 112,1 & $-49,2$ & 46,3 & 140,3 & 927,9 \\
\hline
\end{tabular}

Theo số liệu trên thì công nghiệp năng lượng (trong đó chủ yếu là hoạt động phát điện) là đóng góp chính vào lượng khí thải hiện tại, cũng như thập kỷ tới đều trên $50 \%$, cụ thể: năm 2014 (53,4\%); 2016 (65\%) (Hình 2); 2020: 61,6\%; 2025 (65,5\%); 2030 (69,4\%). Theo báo cáo trong giai đoạn 2000-2014, lĩnh vực năng lượng, cường độ phát thải có xu hướng tăng (từ 0,66 lên 1,87 tấn $\mathrm{CO}_{2}$ tđđ/người). Cường độ phát thải trên một đơn vị GDP của Việt Nam trong lĩnh vực năng lượng $0,92 \mathrm{~kg} \mathrm{CO}$ tđđ/USD năm 2014 cao gấp 2,03 lần so với trung bình chung của thế giới, 3,7 lần so với Nhật Bản; 1,54 lần so với Thái Lan [3]. So với năm 2018 có nhiều nước tăng, nhưng cũng có nhiều nước giảm mức phát thải $\mathrm{CO}_{2}$, trong đó Việt Nam là một trong nước có mức tăng cao nhất $(20,6 \%)$ [10].

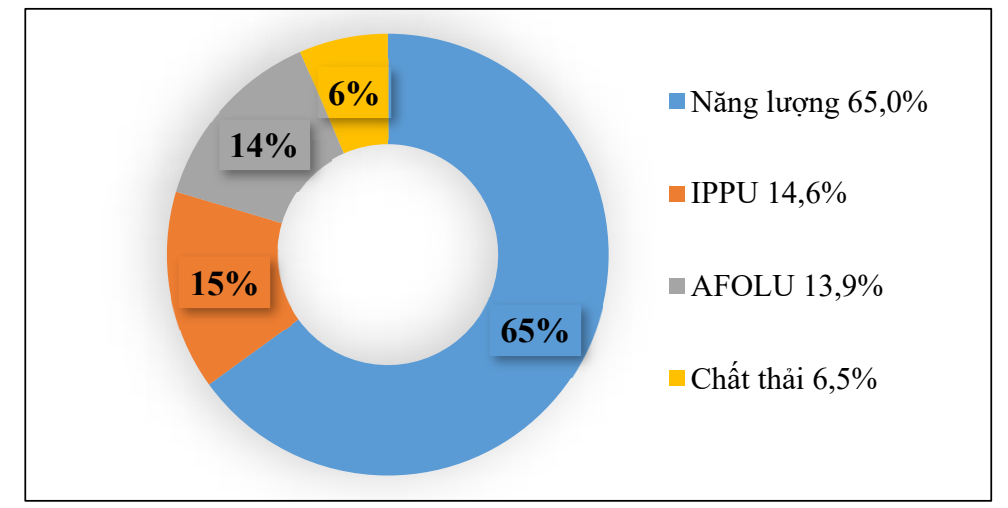

Hình 2. Tỷ trọng phát thải khí nhà kính năm 2016 trong các lĩnh vực [6].

Nhìn vào cơ cấu nguồn điện năm 2020, ta thấy rằng tỷ trọng nhiệt điện than (hiện nay chủ yếu dùng than nội) và thủy điện chiếm vai trò chủ đạo. Trong các công nghệ đốt hiện tại thì các nhà máy điện dùng than nội antraxit có mức phát thải $(\mathrm{kg} / \mathrm{GJ}$ nhiên liệu) là cao nhất. Do đó việc tập trung vào các biện pháp giảm khí thải từ nhiệt điện, cũng như nâng cao hiệu quả vận hành của các nhà máy truyền thống hiện có này sẽ góp phần giảm đáng kể khí nhà kính.

Sự phát triển bùng nổ của năng lượng tái tạo, nhất là điện mặt trời trong khoảng hai năm qua đã gây ra khó khăn cho vận hành hệ thống điện khi mà tỷ trọng điện mặt trời quá lớn nhưng chỉ phát dồn vào buổi trưa, trong khi đó thì phụ tải tăng cao vào giờ cao điểm cuối buổi chiều, tỷ trọng nhiệt điện cao đòi hỏi phải có thời gian nhiều giờ để tăng công suất bù vào thiếu hụt khi công suất điện mặt trời giảm nhanh. Để đảm bảo an toàn cung cấp điện thì điện mặt trời nhiều nơi đã bị bắt buộc cắt giảm làm suy giảm hiệu quả đầu tư. Công suất các nhà máy điện truyền thống biến đổi lớn, tăng chi phí nhiên liệu và chi phí chung của toàn bộ hệ thống. Điều này đặt ra vấn đề cấp bách về tìm kiếm giải pháp sớm cho vận hành cũng như 
trong quy hoạch hệ thống điện trong những năm tới để đảm bảo yêu cầu cung cấp điện ổn định, đáp ứng mục tiêu phải giảm phát thải và chi phí hệ thống điện trong bối cảnh mới.

Theo dự thảo Quy hoạch điện VIII, đến năm 2030 (kịch bản cơ sở) công suất đặt là khoảng $138 \mathrm{GW}$, trong đó nguồn năng lượng gió, mặt trời là $26,5 \%$, than $27,2 \%$, thủy điện $18 \%$. Như vậy so với Quy hoạch VII thì tỷ lệ nhiệt điện than giảm nhiều. Tỷ trọng than giảm này được bù bằng các nguồn phát thải ít hơn, trong đó tua bin khí sử dụng LNG là $12,1 \%$. [8].

Như vậy, theo Nghị quyết 55 cũng như dự thảo Quy hoạch điện VIII ở trên, có thể thấy với các nhà máy điện thì giải pháp để giảm phát thải nhà kính có thể là cho làm hai nhóm: nhóm thứ nhất là đầu tư mới các nhà máy với phát thải thấp như năng lượng tái tạo (gió, mặt trời), nhiệt điện sử dụng công nghệ tiên tiến siêu tới hạn (SC) hoặc trên siêu tới hạn (USC), các nhà máy điện khí/ khí hóa lỏng (LNG); nhóm thứ hai là nâng cấp công nghệ của các nhà máy điện than hiện có, nhất là hệ thống xử lý khí thải và nâng cao hiệu quả phối hợp vận hành các nhà máy thủy điện nhằm thay thế, giảm chi phí nhiên liệu của hệ thống điện.

Với tỷ trọng năng lượng tái tạo cao trong hệ thống, cần có một số giải pháp sau để đảm bảo đáp ứng phụ tải khi nguồn điện tái tạo, nhất là điện mặt trời không đảm nhận được, giữ ổn định hệ thống:

(a) Đầu tư mới cho hệ thống tích trữ năng lượng (pin tích trữ, xây dựng các nhà máy thủy điện tích năng...).

(b) Mở rộng các nhà máy thủy điện hiện có.

(c) Các nhà máy nhiệt điện (than, khí) truyền thống tăng công suất phát điện bù vào phần công suất thiếu hụt.

(d) Thay đổi chế độ và nâng cao hiệu quả vận hành của các nhà máy thủy điện, phối hợp vận hành các nhà máy thủy điện bậc thang.

Trong các giải pháp trên, thì giải pháp $(\mathrm{a})$ và $(\mathrm{b})$ đều đỏi hòi có vốn đầu tư lớn nhằm tạo công suất dự phòng cho hệ thống. Đối với giải pháp (c) thì với đặc điểm nhà máy có chi phí phát điện cao, nhất là khi nước ta đã phải nhập than và sẽ phải nhập khí cho phát điện (đối với nhiệt điện dùng than nhập hay khí LNG mới hiện nay đều có giá ước tính trên 7 cent $/ \mathrm{kWh}$ ) và điện than có độ linh hoạt thấp (thời gian khởi động máy mất nhiều giờ và tốn chi phí nhiên liệu khởi động). Thêm nữa, cả nhiệt điện than hay khí đều gây phát thải lớn, nhất là $\mathrm{CO}_{2}$. Giải pháp $(\mathrm{d})$ có các ưu điểm sau:

- Thời gian khởi động và đáp ứng phụ tải biến đổi nhanh (vài chục giây đến vài phút);

- Nhiều nhà máy thủy điện có hồ điều tiết dài hạn;

- Các hồ chứa trên bậc thang có thể phối hợp với nhau;

- Chi phí phát điện thấp do không tốn nhiên liệu (chỉ khoảng xấp xỉ 4 UScent/kWh);

- Đây là giải pháp nâng cao hiệu quả vận hành trên hệ thống các hồ chứa thủy điện đã có nên không tốn chi phí đầu tư công trình. Như vậy, sẽ góp phần giảm chi phí đầu tư, nhiên liệu và phát thải của nguồn điện.

Việc tiến hành nhóm giải pháp trên là cần thiết và khả thi, tuy nhiên cần xếp ưu tiên phụ thuộc vào tình hình của hệ thống điện. Giải pháp $(\mathrm{d})$ có thể coi là kinh tế hơn nên trong các nhóm giải pháp trên thì khuyến nghị nên ưu tiên nghiên cứu kỹ lưỡng hơn để thực hiện.

Vì các lý do như phân tích nêu trên, nghiên cứu này sẽ trình bày nghiên cứu cho nhóm giải pháp thứ hai với đối tượng là các nhà máy nhiệt điện và nhà máy thủy điện bậc thang đang vận hành trong hệ thống điện sẽ được trình bày chi tiết ở các phần sau.

\subsection{Phưong pháp nghiên cứu}

Để đánh giá tác dụng của nhóm giải pháp cho đối tượng là hai loại nhà máy điện nói trên, các phương pháp riêng cho từng loại như sau.

Đối với các nhà máy nhiệt điện: sử dụng phương pháp nghiên cứu thu thập số liệu thực địa của các nhà máy, so sánh với yêu cầu tiêu chuẩn môi trường và đánh giá khả năng thực 
hiện. Theo QCVN 22: 2009/BTNMT [11], các nhà máy nhiệt điện phải đáp ứng yêu cầu khí thải nghiêm ngặt hơn. Cụ thể là: sau ngày 31/12/2014, nồng độ (C) của các thông số ô nhiễm làm cơ sở tính toán nồng độ tối đa cho phép trong khí thải sẽ buộc phải sử dụng giá trị cột $\mathrm{B}$, bảng 1 , mục 2.2 trong quy chuẩn thay vì cột $\mathrm{A}$ trước đây, áp dụng đối với các tổ máy nhà máy nhiệt điện hoạt động trước 17/10/2005. Theo đó, đối với các nhà máy mới đang lập dự án hay chuẩn bị xây dựng sau ngày ban hành quy chuẩn thì đã kịp cập nhật chi phí đầu tư và đưa vào hợp đồng mua sắm thiết bị. Như vậy, các nhà máy theo tiêu chuẩn cũ cần phải kiểm tra, đánh giá khả năng cải tạo, nâng cấp.

Các phương pháp nâng cấp cải tạo của nhà máy nhiệt điện được nêu trong nhiều nghiên cứu công nghệ gồm có các hệ thống thiết bị sau: (i) khử khí $\mathrm{NO}_{\mathrm{x}}$ bằng $\mathrm{SCR}$ (Selective Catalytic Reduction); (ii) hệ thống khử bụi bằng ESP (Electrostatic Precipitators); (iii) hệ thống khử khí $\mathrm{SO}_{\mathrm{x}}$ bằng $\mathrm{FGD}$ (Flue Gas Desulfurization) [12-13].

Đối với hệ thống hồ chứa nhà máy thủy điện: sử dụng phương pháp sử dụng mô hình toán vận hành hồ chứa nhà máy thủy điện để đánh giá hiệu quả vận hành.

Mô hình toán cho vận hành hệ thống hồ chứa (VHHTHC)nhà máy thủy điện được chia thành hai nhóm: (i) mô phỏng; (ii) tối ưu gồm: quy hoạch phi tuyến, quy hoạch động (dynamic programming-DP) quy hoạch tuyến tính [14-16]. Ở Việt Nam, cũng có một số nghiên cứu như: ứng dụng mô hình MIKE 11 mô phỏng vận hành hệ thống liên hồ cắt giảm lũ cho hạ du Lưu vực sông Srepok [17]; mô hình toán vận hành điều tiết tối ưu hệ thống hồ chứa thủy điện áp dụng cho Sông Bung 2 và Sông Bung 4 [18]; nghiên cứu vận hành tối ưu sử dụng thuật toán quy hoạch động cho hai hồ Sơn La-Hòa Bình trong mùa cạn [19]; nghiên cứu phối hợp vận hành phát điện sau khi mở rộng thủy điện Hòa Bình [20].

Trong các mô hình toán thì mô hình tối ưu, quy hoạch động (DP) là rất phù hợp với VHHTHC khi mà do: (1) Bài toán VHHTHC ra quyết định cho từng giai đoạn kế tiếp nhau khi mà dung tích là biến trạng thái và dòng chảy là biến quyết định; (2) DP cho phép giải quyết bài toán phi tuyến (3) Hiệu quả khi mà số ràng buộc tăng lên vì số lần lặp sẽ giảm đi. Các nghiên cứu đã chỉ rõ hiệu quả của phương pháp này cùng với tốc độ xử lý của máy tính phát triển hiện nay. Thuật toán DP vi phân rời rạc (Descrete Differential $D P-D D D P$ ) được mô tả chi tiết ở $[14,21]$ sẽ thu hẹp nhanh các tổ hợp mực nước và tăng tốc độ tính toán cho hệ thống hồ chứa.

Các công thức của mô hình DP cho hệ thống hồ chứa như sau:

Hàm mục tiêu: Vậy hàm mục tiêu của HTHC theo tiêu chuẩn điện lượng tổng cộng HTHC lớn nhất được chọn (với mỗi bước thời đoạn không đổi $\Delta \mathrm{T}=01$ tháng) sẽ là:

$$
\sum E_{t+1}^{*}\left(V_{t+1}\right)=\operatorname{Max}_{Q t}\left\{\sum E_{t}^{*}\left(V_{t}\right)+E_{t}\left(V_{t}, Q_{t}\right)\right\}
$$

Trong đó $\mathrm{E}^{*} \mathrm{t}+1$ sẽ là điện lượng lớn nhất lũy tích của chuỗi giá trị tại trạng thái $\mathrm{V}$ tương ứng tính đến thời điểm $\mathrm{t}+1$. Đối với hệ thống hồ chứa thì $\mathrm{V}_{\mathrm{t}}$ và $\mathrm{Q}_{\mathrm{t}}$ phải hiểu là tập hợp các biến trạng thái $\mathrm{V}(\mathrm{i}, \mathrm{j})$ và biến quyết định $\mathrm{Q}(\mathrm{i}, \mathrm{j}) ; \mathrm{i}=1$ đến $\mathrm{N}$ là số thời đoạn; $\mathrm{j}=1$ đến $\mathrm{M}$ là số hồ.

Điện lượng thành phần của hồ $\mathrm{i}$, phát trong thời đoạn $\mathrm{j}$ được tính bằng công thức:

$$
E_{(i, j)}=9,81 \cdot \eta_{(i, j)} Q_{p d(i, j)} \cdot H_{(i, j)} \cdot \Delta T
$$

trong đó $\mathrm{E}_{\mathrm{t}}$ là điện lượng phát trong thời đoạn $\Delta \mathrm{T} ; \eta$ là hiệu suất nhà máy; $\mathrm{Q}_{\mathrm{pd}}$ và $\mathrm{H}$ lần lượt là lưu lượng và cột nước phát điện sau khi đã trừ tổn thất; $\eta, Q, H$ phụ thuộc vào đặc tính tua bin và $\eta=\mathrm{f}(\mathrm{Q}, \mathrm{H})$.

Hàm chuyển trạng thái:

$$
\mathrm{V}_{\mathrm{i}, \mathrm{j}+1}=\mathrm{V}_{\mathrm{i}, \mathrm{j}}+(\mathrm{C}(\mathrm{i}, \mathrm{j}) \cdot \mathrm{Qd}(\mathrm{i}, \mathrm{j})+\mathrm{Qkg}(\mathrm{i}, \mathrm{j})-\mathrm{Qtt}(\mathrm{i}, \mathrm{j})-\mathrm{Qyc}(\mathrm{i}, \mathrm{j})-\mathrm{Qpd}(\mathrm{i}, \mathrm{j})) \cdot \Delta \mathrm{T}
$$

Trong đó $\mathrm{V}_{\mathrm{i}, \mathrm{j}}$ là dung tích hồ đầu thời đoạn; $\mathrm{V}_{\mathrm{i}+1, \mathrm{j}}$ là dung tích hồ cuối thời đoạn; $\mathrm{C}$ là ma trận thể hiện sự kết nối dòng chảy trong hệ thống thể hiện độ trễ và chứa nước của dòng chảy trong hệ thống. Với lưu vực nhỏ và thời đoạn tính toán là tháng thì $\mathrm{C}=1$ (tức là không có trễ); $\mathrm{Q}_{\mathrm{d}}$ là lưu lượng thiên nhiên đến hoặc từ hồ chứa thượng lưu; $\mathrm{Q}_{\mathrm{kg}}$ là dòng chảy khu giữa; 
$\mathrm{Q}_{\mathrm{tt}}$ là tổn thất (xả, bốc hơi, thấm và các tổn thất khác); $\mathrm{Q}_{\mathrm{yc}}$ là lưu lượng chuyển ra từ hồ do yêu cầu dùng nước thượng lưu; $\mathrm{Q}_{\mathrm{pd}}$ là lưu lượng phát điện. Các ràng buộc (với $\left.\mathrm{t}=1, \ldots, \mathrm{T}\right)$ :

$$
\begin{gathered}
\left.\mathrm{V}_{\min }(\mathrm{i}, \mathrm{j}) \leq \mathrm{V}_{(\mathrm{i}, \mathrm{j}}\right) \leq \mathrm{V}_{\max }(\mathrm{i}, \mathrm{i}) \\
\mathrm{Q}_{\mathrm{pdmin}}(\mathrm{i}, \mathrm{j}) \leq \mathrm{Q}_{\mathrm{pd}}(\mathrm{i}, \mathrm{j}) \leq \mathrm{Q}_{\text {pdmax }}(\mathrm{i}, \mathrm{j}) \\
\mathrm{N}_{\min }(\mathrm{i}, \mathrm{j}) \leq \mathrm{N}(\mathrm{i}, \mathrm{i}) \leq \mathrm{N}_{\max }(\mathrm{i}, \mathrm{i})
\end{gathered}
$$

Trong đó $\mathrm{V}_{\min }$ và $\mathrm{V}_{\max }$ là dung tích (hoặc khống chế qua mực nước) nhỏ nhất và lớn nhất cho phép; $Q_{\min }$ và $Q_{\max }$ là lưu lượng nhỏ nhất và lớn nhất cho phép qua tua bin; $\mathrm{N}_{\min } \mathrm{và}_{\mathrm{max}}$ là công suất nhỏ nhất và lớn nhất (khả dụng) cho phép lấy từ đặc tính thiết bị (hoặc theo yêu cầu hệ thống điện).

Trong nghiên cứu này sử dụng thuật toán $\mathrm{DP}$ vi phân rời rạc (Descrete Differential DP$D D D P$ [ [21]. Mô hình $\mathrm{DP}$ sử dụng thuật toán $\mathrm{DDDP}$ được tác giả thực hiện trên lập trình ngôn ngữ Visual Basic for Applications (VBA).

Nhà máy thủy điện áp dụng trong nghiên cứu này là thủy điện Sông Hinh trong hệ thống hồ chứa thủy điện sông $\mathrm{Ba}$, với các thông số công trình như mô tả ở Bảng 2 . Hệ thống hồ chứa ngoài nhiệm vụ phát điện, còn thỏa mãn yêu cầu phòng lũ và dùng nước hạ lưu, nhất là yêu cầu tối thiểu tại đập dâng Đồng Cam (Hình 3) theo quy trình liên hồ [22].

Bảng 2. Các thông số chính của các hồ chứa và nhà máy thủy điện trong hệ thống.

\begin{tabular}{clccccc}
\hline STT & \multicolumn{1}{c}{ Thông số } & Đơn vị & Ayun Hạ & $\begin{array}{c}\text { Krông } \\
\text { H'Năng }\end{array}$ & $\begin{array}{c}\text { Sông Ba } \\
\text { Hạ }\end{array}$ & $\begin{array}{c}\text { Sông } \\
\text { Hinh }\end{array}$ \\
\hline I & Hồ chứa & & & & & \\
1 & MNDBT & $\mathrm{m}$ & 204 & 255 & 105 & 209 \\
2 & MNC & $\mathrm{m}$ & 195 & 242,50 & 101 & 196 \\
3 & Dung tích hữu ích (Whi) & $10^{6} \mathrm{~m}^{3}$ & 201 & 108,5 & 165,9 & 323 \\
II & Nhà máy thủy điện & & & & & \\
1 & Công suất lắp máy & $\mathrm{MW}$ & 3,0 & 64,0 & 220 & 70,0 \\
2 & Công suất đảm bảo (90\%) & $\mathrm{MW}$ & 2 & 12,1 & 33,3 & 22,9 \\
3 & Lưu lượng lớn nhất (Qmax) & $\mathrm{m}^{3} / \mathrm{s}$ & 23,4 & 68,0 & 393 & 57,3 \\
4 & Cột nước tính toán (Htt) & $\mathrm{m}$ & 14 & 108 & 62 & 141 \\
\hline
\end{tabular}

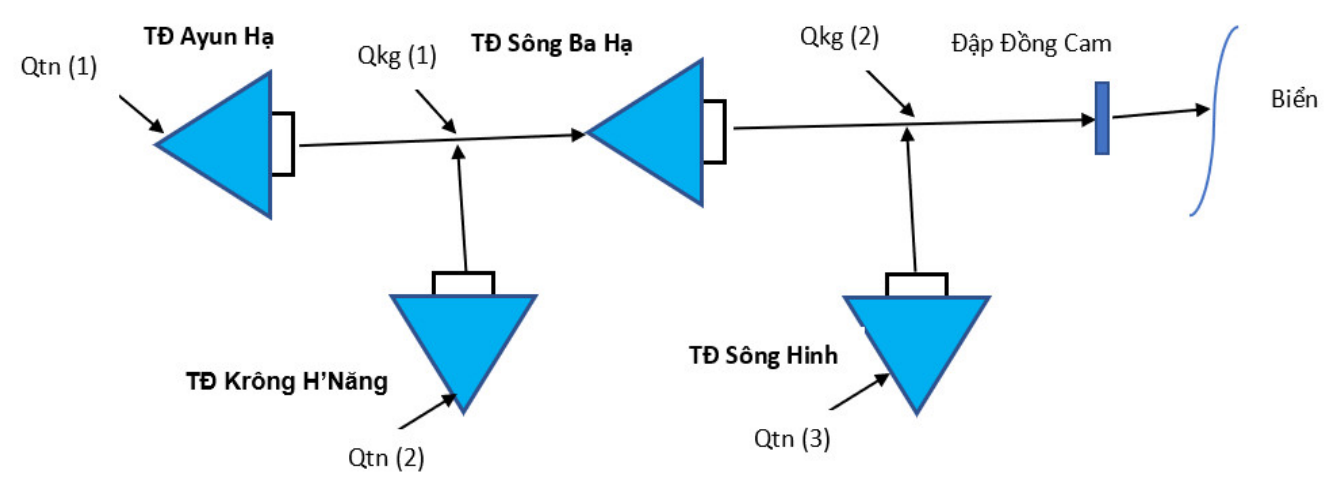

Hình 3. Sơ đồ minh họa hệ thống bốn hồ chứa trên lưu vực sông Ba.

\section{Kết quả và thảo luận}

3.1. Giải pháp nâng cấp các nhà máy nhiệt điện hiện có đáp ứng yêu cầu bảo vệ môi truờng 
Trên cở sở thu thập tài liệu từ các nhà máy nhiệt điện đang vận hành cho thấy các nhà máy điện gồm Phả Lại $1 \& 2$, Hải Phòng $1 \& 2$, Quảng Ninh $1 \& 2$, Uông Bí 2 \& mở rộng được thiết kế theo tiêu chuẩn cũ cần phải nâng cấp hệ thống khí thải hoặc nếu không đạt sẽ phải đóng cửa. Do vậy, các chủ đầu tư nhà máy gồm đã lập và phê duyệt dự án đầu tư trong khoảng năm 2017-2018 để lắp thêm hay cải tạo nâng cấp hệ thống khử $\mathrm{NO}_{\mathrm{x}}(\mathrm{SCR})$, lọc bụi (ESP), khử $\mathrm{SO}_{\mathrm{x}}(\mathrm{FGD})$ nhằm đảm bảo yêu cầu môi trường. Tuy nhiên vào thời điểm đó, việc giá phát điện tăng lên do tăng vốn đầu tư phát sinh cho nhà máy do nâng cấp cải tạo chưa được Chính phủ và Bộ ngành phê duyệt, yêu cầu rà soát lại quy chuẩn và lộ trình áp dụng nên dự án đã tạm dừng.

Với thông tư số 57/2020/TT-BCT [23] mới ban hành về hướng dẫn hợp đồng mua bán điện, đã cho phép bổ sung chi phí cần thiết đầu tư nâng cấp hệ thống xử lý khí thải để đáp ứng yêu cầu theo quy chuẩn kỹ thuật môi trường quốc gia thì việc khởi động lại các dự án là khả thi. Tháng 7/2021, Bộ Tài nguyên và Môi trường (TNMT) cũng vừa ban hành dự thảo quy chuẩn kỹ thuật môi trường quốc gia về bụi, khí thải công nghiệp trong đó bao hàm QCVN 22: 2009/BTNMT về khí thải của các nhà máy nhiệt điện. Nghị quyết 55 cũng đã nêu rõ là "kiên quyết đóng cửa đối với các nhà máy không thực hiện nâng cấp công nghệ theo quy định". Như vậy, chủ đầu tư các nhà máy điện đã có đầy đủ cơ sở pháp lý, cũng như cách thức thu lại khoản tiền vốn đầu tư thêm cho cải tạo, nâng cấp hệ thống xử lý khí thải. Tuy nhiên, hiện nay quá trình tái khởi động còn chậm, các cơ quan chức năng và các tập đoàn như EVN đang đốc thúc chủ đầu tư các nhà máy cập nhật quy địinh liên quan, thực hiện việc nâng cấp sớm hệ thống xử lý môi trường, vừa đảm bảo tiêu chuẩn môi trường và giảm phát thải của hệ thống điện.

Số liệu đối với dự án nhiệt điện Hải Phòng cho thấy hiện nay cả phát thải $\mathrm{NO}_{\mathrm{x}}$ và $\mathrm{SO}_{\mathrm{x}}$ đều cao gần gấp hai lần phát thải cho phép theo QCVN22:2009/BTNMT, nhà máy cần phải lắp thêm hệ thống khử NOx (SCR) và nâng cấp hệ thống khử lưu huỳnh (FGD) (Bảng 3 ). Như vậy, việc cải tạo, nâng cấp sẽ giảm phát thải rõ rệt.

Bảng 3. Thông số phát thải của nhà máy nhiệt điện Hải Phòng (Công ty NĐHP).

\begin{tabular}{|c|c|c|c|}
\hline $\begin{array}{c}\text { Thông số ô } \\
\text { nhiễm }\end{array}$ & $\begin{array}{l}\text { Nồng độ tối đa cho phép theo } \\
\text { TKKT được phê duyệt, } \\
\text { mg/Nm³ (TCVN 5945-1995) }\end{array}$ & $\begin{array}{c}\text { Nồng độ phát thải thực } \\
\text { tế, } \mathbf{m g} / \mathbf{N m}^{3}\end{array}$ & $\begin{array}{c}\text { Nồng độ phát thải phải thay } \\
\text { đổi, mg/Nm }{ }^{3}\left(K_{\mathrm{p}}=0,85 ;\right. \\
\left.K_{\mathrm{v}}=0,6\right) \mathrm{QCVN22:} \\
2009 / \mathrm{BTNMT})\end{array}$ \\
\hline Bụi & 100 & $80-100$ & 102 \\
\hline $\mathrm{SO}_{\mathrm{x}}$ & 500 & $400-500$ & 255 \\
\hline $\mathrm{NO}_{\mathrm{x}}$ & 1000 & $700-1000$ & 510 \\
\hline
\end{tabular}

\subsection{Giải pháp phối hợp và nâng cao hiệu quả vận hành nhà máy thủy điện}

Trên cơ sở số liệu thực tế vận hành thu thập được của nhà máy thủy điện Sông Hinh trong 5 năm (2001-2005), lúc đó hệ thống có bốn nhà máy là Ayun Hạ, Krông H'năng, Sông $\mathrm{Ba}$ Hạ, Sông Hinh vận hành phát điện, mô hình DP được áp dụng để so sánh. Theo quy trình vận hành hệ thống hồ chứa, lưu lượng phải đảm bảo cho đập dâng Đồng Cam để phục vụ cấp nước tưới cho nông nghiệp được đưa vào ràng buộc cấp nước của hệ thống tối thiểu là 30 $\mathrm{m}^{3} / \mathrm{s}$ (thời kỳ cấp nước gia tăng từ tháng 12 đến tháng 3 ), $40 \mathrm{~m}^{3} / \mathrm{s}$ (thời kỳ cấp nước bình thường từ tháng 4 đến tháng 5) [22].

Trên cơ sở số liệu khí tượng thủy văn trên lưu vực và dòng chảy khu giữa, kết quả mô hình tính toán mô hình tối ưu DP, thời đoạn tính toán là một $(01)$ tháng cho hệ thống cho thấy sản lượng điện phát ra trung bình năm tăng lên là 380,7 (triệu $\mathrm{kWh}$ ) so với sản lượng điện trung bình năm thực tế phát trong 5 năm là 369,5 (triệu $\mathrm{kWh}$ ), tương đương với tăng khoảng $3 \%$. 


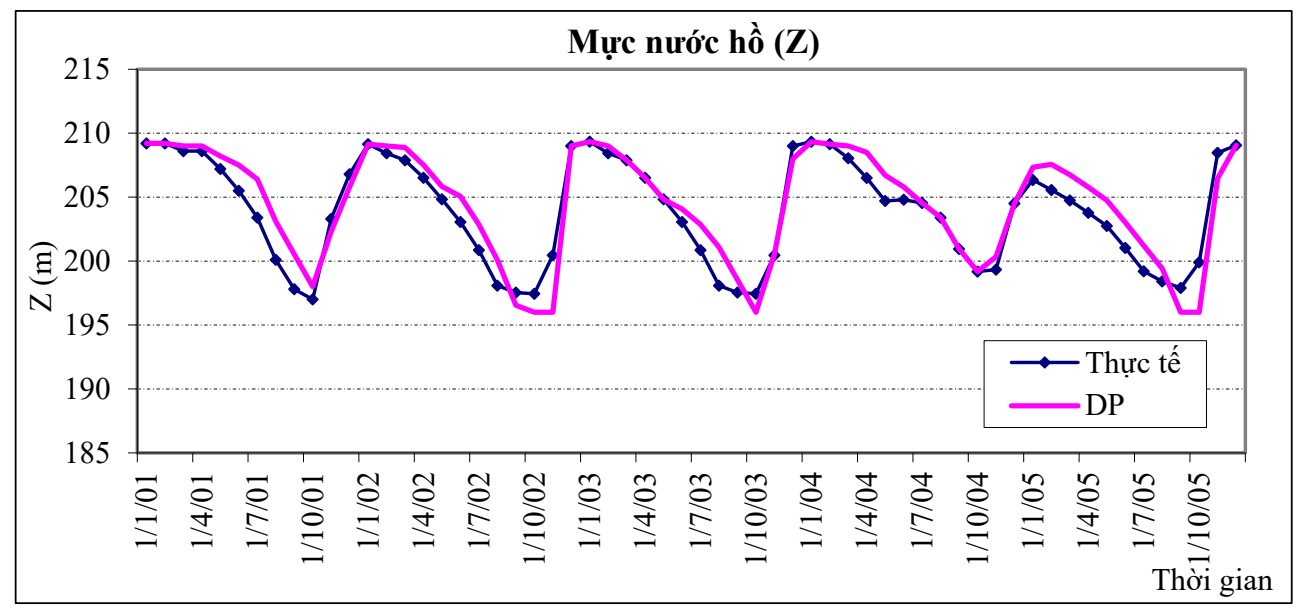

Hình 4. So sánh giữa mực nước hồ các tháng thực tế và mô hình DP (2001-2005).

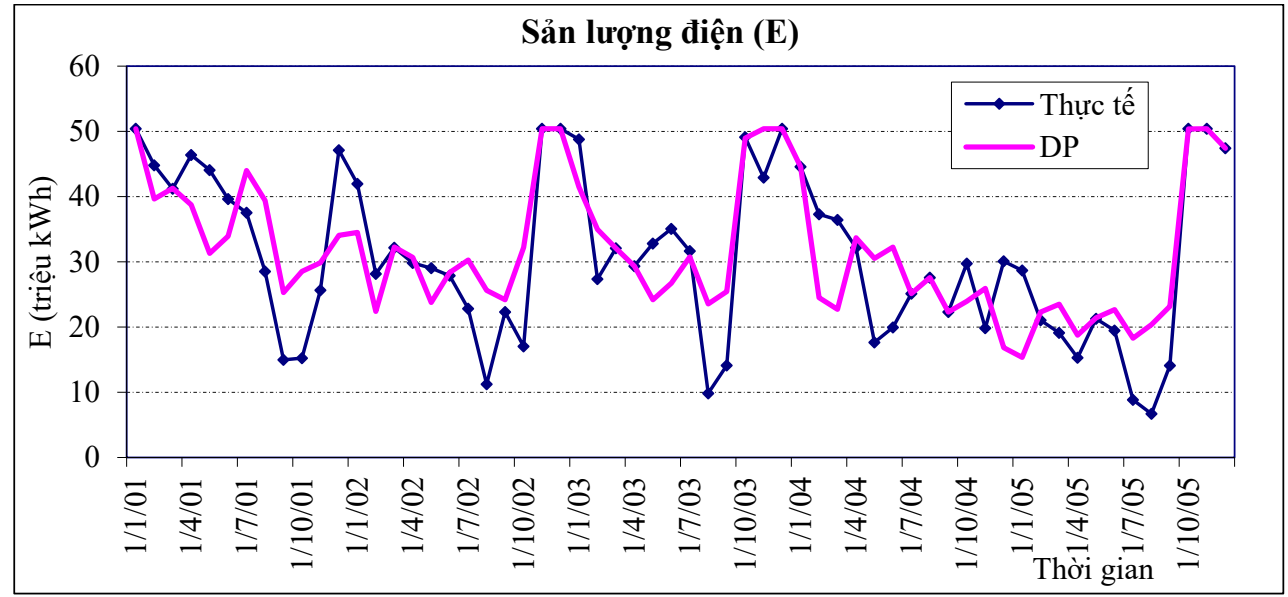

Hình 5. So sánh giữa điện lượng các tháng thực tế và mô hình DP (2001-2005).

Hình 4 cho thấy so sánh giữa mực nước của tính toán và thực tế cho thấy mô hình phối hợp giữa các hồ chứa cho mực nước Sông Hinh luôn ở mực nước cao hơn trong khi vẫn thỏa mãn yêu cầu cấp nước ở đập Đồng Cam, do vậy cho kết quả cho điện lượng trung bình năm là cao hơn (Hình 5).

Như vậy, ví dụ tính toán trên cho thấy việc phối hợp vận hành tốt sẽ nâng cao được hiệu quả vận hành của các nhà máy thủy điện trong khi vẫn thỏa mãn mục tiêu cấp nước cho ngành khác. Tuy nhiên, có một số hạn chế hay ràng buộc chính cần lưu ý khi thực hiện giải pháp nâng cao hiệu quả vận hành của thủy điện là: vận hành phụ thuộc nhiều vào điều kiện thủy văn, hồ chứa thủy điện đa mục tiêu còn đảm nhận các mục tiêu khác (cấp nước, đảm bảo dòng chảy tối thiểu hạ lưu, phòng lũ...), chủ đầu tư của các nhà máy trên hệ thống bậc thang có thể khác nhau nên đòi hỏi có cơ chế phối hợp và điều phối tổng thể của cơ quan chức năng.

Hiện nay thì độ tin cậy của công tác dự báo thủy văn ngày càng được nâng cao, tạo điều kiện thuận lợi cho việc vận hành hồ chứa thủy điện. Theo kết quả các nghiên cứu gần đây đối với một số bậc thang thủy điện cho thấy việc phối hợp vận hành tối ưu sẽ nâng cao rõ rệt hiệu quả phát điện của hồ chứa có dung tích điều tiết dài hạn. Mức tăng sản lượng điện hay doanh thu của từng nhà máy có thể tăng trung bình khoảng 3-5\% tùy vào đặc tính của từng hồ chứa và dòng chảy đến [14-21]. Điều này rất có ý nghĩa rất lớn khi mà Việt Nam có nhiều hồ chứa và tỷ trọng thủy điện vẫn đóng quan trong trong hệ thống điện. Đặc biệt trong nhiệm vụ điều tần, giữ ổn định, tiết kiệm nhiên liệu ở nhiệt điện, giảm phát thải của hệ thống điện như đã đề cập ở trên. 


\section{Kết luận}

Qua phân tích trên, trong các nhóm giải pháp để giám khí thải, vận hành ổn định và giảm chi phí của hệ thống điện thì giải pháp nâng cấp cải tạo các nhà máy nhiệt điện hiện có, nâng cao vận hành hệ thống nhà máy trên bậc thang thủy điện là giải pháp kinh tế, có tính khả thi cao và hoàn toàn chủ động phát huy "nội lực" được, nên được ưu tiên nghiên cứu thực hiện. Do vậy, khuyến nghị cơ quan có thẩm quyền có sự quan tâm nghiên cứu và cơ chế chính sách khuyến khích lồng ghép vào hợp đồng mua bán điện với các nhà máy điện, đầu tư nâng cấp hệ thống xử lý khí thải nhiệt điện, cơ chế phối hợp các chủ đầu tư nhà máy thủy điện và vai trò quản lý, điều phối các cơ quan ban ngành liên quan để nâng cao vận hành hệ thống nhà máy trên bậc thang thủy điện, đảm bảo an ninh cung cấp điện, giảm khí thải, giảm chi phí hệ thống điện, đóng góp vào việc bảo vệ môi trường và chống biến đổi khí hậu, phát triển kinh tế đất nước.

Đóng góp của tác giả: Tác giả đã xây dựng ý tưởng nghiên cứu, lựa chọn phương pháp nghiên cứu, xử lý số liệu, viết bản thảo bài báo và chỉnh sửa bài báo.

Lời cảm ơn: Tác giả trân trọng cảm ơn sự giúp đỡ của các cơ quan trực thuộc Bộ Công thương gồm: Cục điện lực và Năng lượng tái tạo, Viện Năng lượng; Tổng Cục môi trường (Bộ Tài nguyên và Môi trường); Tập đoàn điện lực Việt Nam; Bộ môn Thủy điện và Năng lượng tái tạo (Trường Đại học Thủy lợi) trong quá trình khảo sát, thu thập số liệu và thực hiện nghiên cứu này.

Lời cam đoan: Tác giả cam đoan bài báo này là công trình nghiên cứu của chính tác giả, chưa được công bố ở đâu, không được sao chép từ những nghiên cứu trước đây; không có sự tranh chấp lợi ích.

\section{Tài liệu tham khảo}

1. Quyết định số 428/QĐ-TTg của Thủ tướng Chính phủ ngày 18/3/2016 về Điều chỉnh Quy hoạch Phát triển điện lực Quốc gia giai đoạn 2011-2020, tầm nhìn đến năm 2030, 2016.

2. Quyết định số 2053/QĐ-TTg của Thủ tướng Chính phủ ngày 28/10/2016 ban hành Kế hoạch hành động thực hiện Thỏa thuận Paris về Biến Đổi Khí hậu, 2016.

3. Hiếu, N.V.; Nam, N.H. Hiện trạng phát thải khí nhà kính tại Việt Nam: Cơ hội và thách thức. Tạp chi Khi tuợng Thủy văn 2021, 728, 41-66.

4. Bộ Tài nguyên và Môi trường. Báo cáo kỹ thuật Đóng góp dự kiến do Quốc gia tự quyết định của Việt Nam (INDC), 2015.

5. Bộ Tài nguyên và Môi trường. Thông báo quốc gia lần thứ ba của Việt Nam cho Công ước khung của Liên Hợp Quốc về Biến đổi khí hậu, 2019.

6. Bộ Tài nguyên và Môi trường. Báo cáo kỹ thuật đóng góp do quốc gia tự quyết định của Việt Nam (cập nhật năm 2020), 2020.

7. Nghị quyết của Bộ Chính trị số 55-NQ/TW ngày 11/2/2020 về định hướng chiến lược phát triển năng lượng quốc gia của Việt Nam đến năm 2030, tầm nhìn đển năm 2045, 2020.

8. Viện Năng lượng. Đề án Quy hoạch phát triển điện lực quốc gia thời kỳ 2021-2030, tầm nhìn đến năm 2045 (Quy hoạch Điện 8) - Dự thảo lần 3, tháng 3/2021.

9. Bộ Tài nguyên và Môi trường. Báo cáo cập nhật hai năm một lần lần thứ nhất của Việt Nam cho Công ước khung của Liên Hợp Quốc về Biến đổi khí hậu, 2014.

10. Nam, N.C. Phát thải $\mathrm{CO}_{2}$ từ ngành năng lượng: số liệu của thế giới và Việt Nam. Tạp chí Năng lương nhiệt, Hội Khoa học Kỹ thuật Nhiệt Việt Nam 2021, 155, 3-7.

11. Bộ Tài nguyên và Môi trường. Quy chuẩn kỹ thuật quốc gia về khí thải công nghiệp nhiệt điện số QCVN 22:2009/BTNMT, ban hành theo Thông tư số 25/2009-TTBTNMT ngày 16/11/2009.

12. General Electric. AQCS (Air Quality Control System) for Thermal Power Plants. Available online: https://www.ge.com/steam-power/products/aqcs. 
13. Mitsubishi Heavy Industries. AQCS Research \& Development. Available online: https://power.mhi.com/products/aqcs/environmenta-technology.

14. Labadie, J.W. Optimal Operation of Multireservoir Systems: State-of-the-Art Review. J. Water Resour. Plann. Manage. 2004, 30(2), 93-11.

15. SamadAzad, A.; Md Shokor Rahaman, A.; Junzo, W.; Pandian, Vasant.; Jose, A.G.V. Optimization of the hydropower energy generation using Meta-Heuristic approaches: A review. Energy Rep. 2020, 6, 2230-2248.

16. Mumtaz, A.; Elcin, K.; Secil, S. Operating Policies for Energy Generation and Revenue Management in Single-Reservoir Systems. Renewable Sustainable Energy Rev. 2017, 78, 1253-1261.

17. Long, N.L. Ứng dụng mô hình Mike 11 mô phỏng vận hành hệ thống liên hồ cắt giảm lũ cho hạ du - Lưu vực sông Srepok. Tạp chí Khoa học kỹ thuật Thủy lợi \& Môi truờng 2011, 32, 27-33.

18. Hùng, L. Mô hình toán vận hành điều tiết tối ưu hệ thống hồ chứa thủy điện - áp dụng cho Sông Bung 2 và Sông Bung 4. Tạp chí Khoa học kỹ thuật Thủy lợi \& Môi trường 2011, 32, 98-103.

19. Dung, H.N. Nghiên cứu lựa chọn tiêu chuẩn tối ưu vận hành hồ chứa bậc thang thủy điện làm việc trong hệ thống điện lực. Tạp chi Khoa hoc Thủy lợi và Môi trường, 2017, 58, 41-47.

20. Long, P.T.H. Nghiên cứu các phương thức phối hợp vận hành phát điện sau khi mở rộng thủy điện Hòa Bình. Tạp chi Khi tượng Thủy văn 2020, 712, 42-48.

21. Sơn, L.N.; Thành, L.Đ. Nghiên cứu ứng dụng quy hoạch động vi phân rời rạc vận hành hồ thủy điện sông Hinh. Tạp chí Khí tuợng Thủy văn 2017, 676, 31-36.

22. Quyết định số 878/QĐ-TTg của Thủ tướng Chính phủ ngày 18/7/2018 ban hành quy trình vận hành liên hồ chứa trên lưu vực sông $\mathrm{Ba}, 2018$.

23. Bộ Công Thương. Thông tư số 57/2020/TT-BCT ban hành ngày 31/1/2020 về việc Quy định phương pháp xác định giá phát điện, hợp đồng mua bán điện, 2020.

\title{
Some countermeasures of operational improvement and green house gas emission reduction, contributing to climate change prevention for coal-fired and hydropower plants operating in Vietnam power system in the new context
}

\section{Le Ngoc Son ${ }^{1}$}

${ }^{1}$ Thuy loi University; lengson99@gmail.com

\begin{abstract}
Currently traditional power plants including coal-fired and hydropower together has been holding dominant role in electricity production for Vietnam power system. However, in recent years and coming time, with international and Vietnam's commitment on green house gas emission reduction, there has been significant movement of energy structure in power system and role of traditional power plants shall be changed. This article analyzes the status of power system and increase in renewable energy (solar, wind) in the system, then provides assessment of resolutions and proposes to prioritize two among these resolutions as: (i) to upgrade air quality control system (AQCS) of some coal-fired power plant; (ii) to improve operational performance of hydropower cascade system to ensure stability and reduce overall cost and green house gas emission of power system.
\end{abstract}

Keywords: Power system; Green house gas emission; Air quality control system of coalfired power plant; Hydropower reservoir system operation optimization. 